\title{
CONTRIBUIÇÕES ACADÊMICAS DOS MESTRES E DOUTORES DO DEPARTAMENTO DE CIÊNCIAS CONTÁBEIS DAS UNIVERSIDADES ESTADUAIS DO PARANÁ: UM ESTUDO COM BASE NOS CURRÍCULOS DA PLATAFORMA LATTES
}

\section{ACADEMIC CONTRIBUTIONS OF MASTERS AND DOCTORS OF THE DEPARTMENT OF ACCOUNTANCY OF STATE UNIVERSITIES OF PARANÁ: A STUDY BASED ON THE RESUMES OF LATTES PLATFORM}

\author{
Patricia Taradenko ${ }^{1}$; Ana Léa Macohon Klosowski ${ }^{2}$ \\ ${ }^{1}$ Universidade Estadual do Centro-Oeste - UNICENTRO - Brasil \\ paty_taradenko@hotmail.com \\ ${ }^{2}$ Universidade Estadual do Centro-Oeste - UNICENTRO - Brasil \\ alea@irati.unicentro.br
}

\begin{abstract}
Resumo
Este artigo apresenta as Contribuições Acadêmicas dos Mestres e Doutores do Departamento de Ciências Contábeis das Universidades Estaduais do Paraná, com base nos currículos disponibilizados na Plataforma Lattes. As contribuições acadêmicas podem desenvolvidas de inúmeras maneiras, seja pelas participações em grupos e projetos de pesquisa, pelas atividades de extensão, ou então pelas publicações de artigos no meio acadêmico. Entretanto, nota-se que apenas o seu desenvolvimento não seja o suficiente. É preciso que além de sua criação, este conhecimento chegue ao alcance de toda comunidade acadêmica. A metodologia aplicada neste estudo caracteriza como descritiva, do tipo survey e bibliográfica com abordagem qualitativa $e$ quantitativa. A população compreende todos os professores mestres e doutores do departamento de contabilidade das sete universidades estaduais do Paraná, um total de 128 profissionais. Para o levantamento foi selecionada uma amostra de 121 docentes; profissionais estes que disponibilizaram no site do $\mathrm{CNPq}$ suas informações curriculares.
\end{abstract}

Palavras-chave: Docentes; Universidades Estaduais do Paraná; Pesquisa Cientifica.

\section{Introdução}

A sociedade atual passa por um período de transformações, um novo ideal, onde atitudes sustentáveis aliadas ao conhecimento humano são fatores preponderantes para o desenvolvimento social. Mudanças que criam novos valores, baseados na busca constante pela educação como a força fundamental de todo crescimento, seja pessoal ou profissional (LEITE, 2005).

A definição de educar é ampla, sendo conceituada na maioria das vezes como a arte de ensinar, de formar, desenvolver conhecimentos físicos, morais e intelectuais. Um conhecimento que começa no seio da família, continua na escola e se prevalece ao longo de sua formação profissional (TEMAIO, 2002). 
E através deste processo de educar que o docente se apresenta como um agente primordial de mudanças dentro do ensino. Sua profissão vai além de conhecimentos técnicos e teóricos, nela valores como a ética, a dedicação e a seriedade são a base de transformação de todo conhecimento. De acordo com Vasconcelos (1996) uma das capacidades que devem estar presentes na vida profissional do docente é a investigação adquirida por meio da pesquisa científica.

A pesquisa precisa ser compreendida como: "uma necessidade; um dos maiores e mais importantes desafios para uma educação de qualidade. Essa relevante questão deve ainda ser considerada como promotora da cidadania e do processo emancipatório de cada indivíduo" (FURLAN e NASCIMENTO, 2006, p.02). Em complemento, Beirão (1998, p.01) salienta que: “o desafio da universidade hoje é formar indivíduos capazes de buscar conhecimentos e de saber utilizá-los. Ao contrário de outrora, quando o importante era dominar o conhecimento, hoje penso que o importante é dominar o desconhecimento"”.

O termo "dominar o desconhecimento" significa buscar o conhecimento quando este não está disponível, utilizando-se da pesquisa como o meio fundamental para encontrá-lo (BEIRÃO, 1998). A partir disso, refletir sobre o docente para Furlan e Nascimento (2006, p.02) é: "repensar o professor e recriá-lo, deixando de ser um "repassador" de conteúdos, para tornar-se um mestre, uma pessoa capacitada e qualificada profissionalmente, em consonância com a responsabilidade que carrega e com a importância de sua profissão".

Desse modo, em meio à importância do comprometimento dos docentes com a pesquisa científica, este estudo tem por finalidade identificar: Qual a frequência de contribuições acadêmicas desenvolvidas pelos mestres e doutores do departamento de Ciências Contábeis das universidades estaduais do Paraná? Para tanto, este estudo levantou as contribuições acadêmicas dos professores Mestres e Doutores dos departamentos de Ciências Contábeis nas Universidades Estaduais do Paraná no período de 01/01/2007 a 31/12/2012.

Considera-se de suma importância discutir o cenário atual, devido a relevância que o docente representa no processo de aprendizagem, em especial o profissional da área contábil e que em muitas instituições encontram-se em números insuficientes, seja em função do mercado de trabalho ou pelo reduzido números de especializações Stricto Sensu oferecidas no país.

Ao Evidenciar as contribuições acadêmicas dos professores mestres e doutores das universidades estaduais do Paraná, o presente estudo identificou o comprometimento destes profissionais com a pesquisa científica, bem como o seu envolvimento em atividades acadêmicas da própria instituição. Alem disso, com o material teórico levantado, este estudo pode vir a contribuir para trabalhos posteriores relacionados com a docência Universitária na área da contabilidade. 


\section{Referencial Teórico e Prático}

\subsection{A Teoria do Capital Humano}

O termo capital humano refere-se ao conjunto das capacidades produtivas do homem, que quando desenvolvidas agregam valor intelectual e econômico ao ser humano. Um ativo intangível não negociável; configurando-se como capital em função dos futuros rendimentos que poderá vir a proporcionar e humano, pois faz parte da sua essência (CUNHA, 2007).

A teoria do capital humano apresenta-se em duas perspectivas; $1^{\circ}$ a melhor capacitação do trabalhador como aumento de produtividade para a organização e em $2^{\circ}$ o desenvolvimento de ações individuais na construção de seu capital pessoal a fim de se obter melhor remuneração no mercado (CATTANI, 2002).

Para Cunha (2007, p.28): "a Chave da teoria do capital humano é o conceito de que a aquisição de mais conhecimentos e habilidades aumenta o valor do capital humano das pessoas, aumentando sua empregabilidade, produtividade e rendimento profissional", Ruckstadter (2005, p.04) complementa: "todas as habilidades são inatas ou adquiridas, que podem ser aperfeiçoadas por meio de investimentos apropriados ao enriquecimento do capital intelectual”.

\subsection{A Educação e o Ensino Superior}

A Educação pode ser conceituada como o desenvolvimento de habilidades físicas, morais e intelectuais do ser humano, iniciada no berço da família e com a finalidade de auxiliar o indivíduo no preparo para o exercício da cidadania. Diversos autores comentam sobre o significado da palavra educação; para Klein (1975, p.33): “educar é estimular, orientar para desenvolver aptidões, de acordo com interesses ou de acordo com as convenções sociais, com os ideais de uma sociedade". Andre e Costa (2004, p.8), salientam que a educação é responsável em: “dotar a humanidade da capacidade de dominar o seu próprio desenvolvimento".

A origem da palavra ensino vem do latim in+signare e significa pôr marcas ou sinais, designar e mostrar coisas. Dessa forma, é transmitir conhecimentos que sejam absorvidos pelo sujeito de modo que esse aprendizado atenda suas necessidades, sejam elas pessoais ou profissionais. Já a palavra superior transmite a ideia de algo que está mais alto, de autoridade ou ainda, de maior qualidade que os demais (FERREIRA, 2001).

As finalidades do ensino superior são inúmeras, porém ambas com um único objetivo: constituir profissionais capazes de transformar o conhecimento científico em condutas profissionais e pessoais que contribuíram para sua capacidade de atuação. De acordo com a pesquisa encomendada pelo SEMESP (2008) à empresa Franceschini Análises de Mercado onde ouviu 1.431 profissionais das principais empresas do Estado de São Paulo, concluiu que: "o ensino superior tem 
um papel preponderante para a empregabilidade e a evolução profissional dos jovens recém-saídos das instituições acadêmicas".

O ensino superior é visto como um diferencial no mercado de trabalho, agregando ao indivíduo um valor que o diferencia dos demais. Por meio dele são desenvolvidas aptidões nas mais diversas áreas do conhecimento, essenciais para o futuro exercício da profissão; além de contribuir para o aprofundamento de formações anteriores. Sua íntima relação com a investigação é um dos elementos fundamentais para o desenvolvimento da autonomia e espírito crítico do acadêmico, contribuindo diretamente para o avanço tecnológico, social e cultural (JARDILINO, AMARAL e LIMA 2010).

\subsection{As Universidades Estaduais do Paraná}

Atualmente, o ensino superior paranaense é composto por sete universidades estaduais distribuídas praticamente em todas as regiões do Estado, sendo elas: a Universidade Estadual de Maringá - UEM, Universidade Estadual de Londrina - UEL, Universidade Estadual de Ponta Grossa - UEPG, Universidade Estadual do Oeste do Paraná - UNIOESTE, Universidade Estadual do Centro Oeste do Paraná - UNICENTRO, Universidade Estadual do Paraná - UEPR e a Universidade Estadual do Norte do Paraná - UENP.

A mais recente universidade criada no estado do Paraná é a Universidade estadual do Paraná - UEPR. Constituída em 2010, com sede na cidade de Curitiba, ela representa a junção de diversas faculdades isoladas, transformadas em campi universitários. De acordo com o Jornal Gazeta do Povo de Maringá (2010), a criação da universidade foi uma solução encontrada para reunir as sete faculdades estaduais, gerenciando assim à distribuição de recursos às instituições agregadas.

Com aproximadamente 69,8 mil estudantes de acordo com o Censo da Educação Superior (2010), o ensino universitário Estadual está distribuído em 37 municípios do Paraná, conforme ilustra a Figura 01.

Figura 01 - O ensino universitário estadual

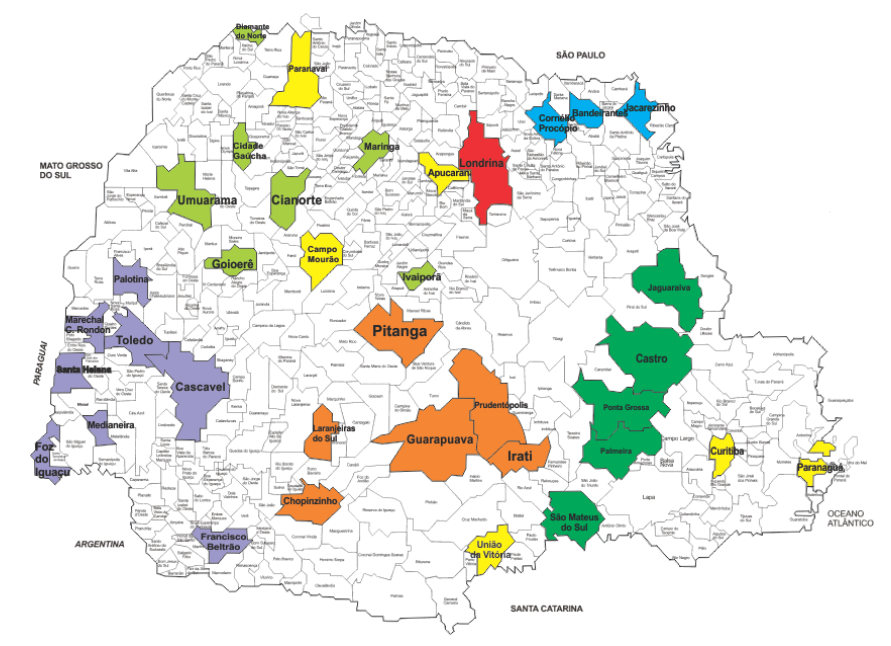



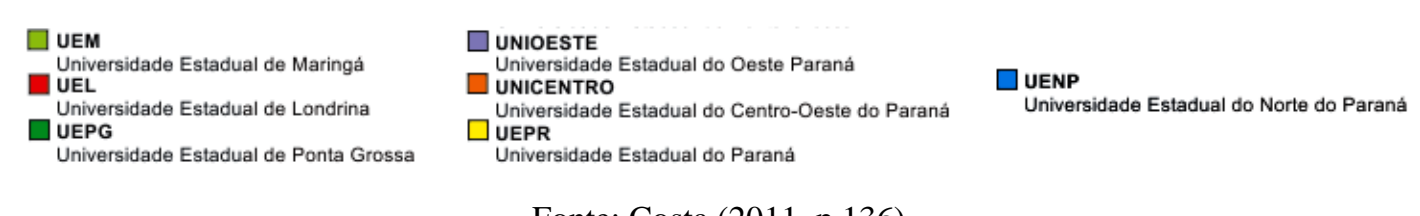

Fonte: Costa (2011, p.136)

Conforme dados apresentados pela Secretaria da Ciência, Tecnologia e Ensino Superior SETI PR (2012), as Universidades Estaduais do Paraná contam com 123.580 alunos matriculados entre os 278 cursos de graduação, 102 cursos de mestrados, 42 cursos de doutorado e também cursos de especialização. Com um total de 6.941 docentes, 5.830 possuem qualificação mestre e doutor, representando $84 \%$ de profissionais atuantes.

\subsection{A Graduação em Contabilidade}

Um importante instrumento de gestão, capaz de fornecer informações necessárias, auxiliando o processo de gestão dentro da organização é a Contabilidade, que para Oliveira (2008) no ponto de vista de seus usuários: "tem o objetivo de prestar informações úteis e relevantes àqueles com interesse na avaliação da situação patrimonial e no desempenho dessas entidades; que podem ser pessoas físicas ou jurídicas, internas ou externas em relação a elas”.

Com um mercado de trabalho promissor e atuação nos mais diversos campos de trabalho, conforme reportagem apresentada pela revista eletrônica G1 (2007): “as possibilidades de emprego são maiores que o tamanho da categoria de bacharéis em contabilidade atuando na área, [...] tendo muitos dos alunos empregados antes mesmo de concluir o curso".

Inúmeros são os campos de atuação para o profissional contábil, que de acordo com Rodrigues (2011), pode atuar como auditor externo, interno e independente, consultor, proprietário de escritório contábil, perito contábil; funcionário público, analista de contabilidade, assessor, docente e também pesquisador na área. Segundo dados apresentados pelo INEP - Instituto Nacional de Estudos e Pesquisas Educacionais Anísio Teixeira (2010), o Curso em Ciências Contábeis é o $6^{\circ}$ maior em número de vagas oferecidas no país, com aproximadamente 380 mil estudantes distribuídos em $16 \%$ da rede pública de ensino e $84 \%$ na particular, sendo também o $5^{\circ}$ maior curso em diplomados no país. Distribuídos em todos os Estados do país, sua maior concentração de cursos ofertados encontra-se na região Sudeste com 502 cursos ofertados, já a região Sul apresenta-se logo em segundo lugar com 252 (INEP, 2010).

\subsection{Formação do Corpo Docente em Contabilidade}

Durante muito tempo no ensino superior não se tinha exigências legais em que se refere à titulação e formação pedagógica de docentes para o ingresso às instituições, onde a concepção era 
de "quem sabe, sabe ensinar", e "o bom professor nasce feito", sendo a competência profissional seu único requisito de seleção (GIL, 2011; NOSSA 1999).

No entanto, a partir da criação das primeiras Universidades na década de 30, verificando a necessidade de maior competência não apenas vivencial, mas também de experiência técnica e pedagógica, o governo desenvolveu ações de melhoria para a docência universitária, como a criação do Estatuto das Universidades Brasileiras a fim de elaborar um programa de Pós-graduação no país com base nos modelos europeus (GIL, 2011).

Dividida em dois sentidos o Lato Sensu e o Stricto Sensu, conforme instrução do MEC (2012): “os cursos de pós-graduação Lato Sensu são voltados para o nível de especialização, mais direcionados à área profissional, de mercado, e com caráter de educação continuada", já o Stricto Sensu, na concepção de VESCO (2006, p.83): “ao contrário das especializações, os interessados devem atender à exigência de executar previamente um projeto, e ao concluir o programa têm suas dissertações e teses qualificadas".

Vinculadas à formação Stricto Sensu, tanto o mestrado como o doutorado tem natureza acadêmica e são desenvolvidos com o intuito de formar e desenvolver pesquisadores com amplo domínio do saber. O professor que assume a postura de pesquisador "compromete-se com a elaboração própria, com o questionamento, com a emancipação política, com a formação da cidadania, com a criatividade, com a descoberta e com a redescoberta" (FURLAN; NASCIMENTO 2006, p.01).

Embora os cursos de mestrados sejam considerados o principal meio institucional de preparação de docentes para o ensino superior, poucas são as instituições que oferecem esta formação. Atualmente, o Brasil dispõe de 22 cursos ofertados na modalidade Stricto Sensu na área da Contabilidade, sendo 17 desses em nível de Mestre e 04 em Doutorado, conforme apresenta a Tabela 01:

Tabela 01 - Cursos de Mestrado e Doutorado em Ciências Contábeis Recomendados e reconhecidos

\begin{tabular}{cccc}
\hline INSTITUIÇÃO & UF & ÁREA DE ATUAÇÃo & NÍVEL \\
\hline UFES & ES & Contabilidade & Mestrado \\
FUCAPE & ES & Contabilidade e Finanças & Mestrado \\
FUCAPE & ES & Contabilidade & Doutorado \\
UFMG & MG & Contabilidade e Controladoria & Mestrado \\
UFPE & PE & Informação Contábil & Mestrado \\
UFRJ & RJ & Contabilidade e Controladoria & Mestrado \\
UERJ & RJ & Controle de Gestão & Mestrado \\
UNISINOS & RS & Contabilidade e Controladoria & Mestrado \\
FURB & SC & Controladoria & Mestrado \\
FURB & SC & Controladoria & Doutorado \\
FURB & SC & Gestão das Organizações & Mestrado \\
UNIFECAF & SP & Controladoria e Contabilidade & Mestrado \\
PUC/SP & SP & Ciências Contábeis e Financeira & Mestrado \\
UFBA & BA & Controladoria & Mestrado \\
UFPR & PR & Contabilidade e Finanças & Mestrado \\
UFPR & PR & Administração & \\
\hline
\end{tabular}




\begin{tabular}{cccc}
\hline UFSC & SC & Controladoria & Mestrado \\
UNB & DF & Mensuração Contábil & Doutorado \\
UNB & DF & Mensuração Contábil & Mestrado \\
USP & SP & Controladoria e Contabilidade & Mestrado \\
USP & SP & Controladoria e Contabilidade & Doutorado \\
USP/RP & SP & Controladoria e Contabilidade & Mestrado \\
\hline
\end{tabular}

Fonte: CAPES (2012), adaptado pela Autora.

Dentre os cursos ofertados sete destes localizam-se na região Sul do país, com área de atuação em Administração, Contabilidade, Finanças, Controladoria e Gestão das Organizações, ambos reconhecidos pelo Ministério da Educação ou então, cujas propostas foram recentemente aprovadas pela CAPES e encaminhadas ao CNE para a instrução de seus processos de reconhecimento.

\subsection{A Plataforma Lattes}

A partir do Currículo Lattes, o CNPq desenvolveu um formato-padrão para coleta de informações curriculares hoje adotadas e requeridas pelo conselho, mas também pela maioria das instituições de ensino superior e institutos de pesquisa no país (LEMES, 2008). Sua disponibilização pública dos dados proporcionam maior transparência e mais confiabilidade às atividades de fomento do $\mathrm{CNPq}$ e das agências que a utilizam, fortalecem o intercâmbio entre pesquisadores e instituições e é fonte inesgotável de informações para estudos e pesquisas, além de preservar a memória da atividade de pesquisa no país (CNPq 2012).

Desde agosto de 1999 a Plataforma Lattes é composta pela integração de cinco sistemas de informações distintos, sendo eles: Currículo Lattes, Diretório dos Grupos de Pesquisa, Diretório de Instituições, Sistema Gerencial de Fomento e Periódicos Lattes. No contexto da Gestão do Conhecimento, a Plataforma Lattes apresenta um grande potencial de geração do conhecimento que pode vir trazer valiosas informações sobre a produção científica e tecnológica desenvolvida em todo o país (LEMES, 2008).

\section{Metodologia da Pesquisa}

A pesquisa foi desenvolvida conforme os objetivos estabelecidos no trabalho, classificando assim, como uma pesquisa descritiva, com o objetivo de apresentar as características acadêmicas dos mestres e doutores das instituições de ensino superior estadual do país, as universidades que integram esse conjunto, bem a composição do corpo docente na área contábil. Uma descrição detalhada de dados que segundo Beuren (2008, p.81), significa: "identificar, relatar, comparar entre outros aspectos".

A coleta de dados neste estudo foi realizada por meio da utilização do site da Plataforma Lattes. Uma base de dados e portais Web voltados para a gestão da Ciência e da Tecnologia, 
composta pela integração de cinco sistemas de informações distintos. Para tanto, os procedimentos adotados para coletar essas informações foi à pesquisa bibliográfica, a documental bem como a de levantamento ou survey.

Com relação à abordagem do problema, esta pesquisa constitui-se de dois desdobramentos, classificando-se tanto como quantitativa como qualitativa. A união das duas modalidades de abordagem proporcionou maior qualidade em relação à descrição de característica do determinado grupo, bem como quantidade, aliado a apresentação dos resultados em números reais e não apenas subjetivos.

A população desta pesquisa foram todos os mestres e doutores que atuam como professores nas Universidades Estaduais do Paraná na graduação em Ciências Contábeis, representando 104 mestres e 24 doutores, um total de 128 docentes. Em busca da amostra que melhor represente o universo a ser estudado, esta pesquisa adotou como critério de seleção os 121 mestres e doutores que possuem currículo cadastrado na Plataforma Lattes.

\section{Análises dos Resultados}

A análise interpretação de resultados foi organizada em duas etapas: na primeira, identificam-se quais são as Universidades Estaduais de ensino superior no Paraná, bem como o número de docentes especialistas, mestres e doutores; na segunda faz-se a discussão das informações obtidas nos currículos destes profissionais.

\subsection{Análises de Dados Gerais}

Dentre todas as instituições analisadas foram identificados um número de 272 docentes, destes 151 professores atuantes como especialistas (55,5\%), 90 mestres $(33,1 \%)$ e apenas 31 Doutores representando $11,4 \%$ do total verificado. Conforme é visualizado no Quadro 01 Contabilistas com formação Lato Sensu e Stricto Sensu, no período de 2012, a porcentagem de professores especialistas atuantes ultrapassa a 50\% em cinco instituições de ensino, com destaque para a UEM e a UEPG, as únicas com percentuais abaixo de $45 \%$.

Quadro 01 - Universidades Estaduais do Paraná - Contabilistas com formação Lato Sensu e Stricto Sensu, 2012.

\begin{tabular}{|l|c|c|}
\hline \multicolumn{1}{|c|}{ INSTITUIÇÕES } & Lato Sensu & Stricto Sensu \\
\hline Universidade Estadual de Londrina & $55,00 \%$ & $45,00 \%$ \\
\hline Universidade Estadual de Maringá & $40,54 \%$ & $59,46 \%$ \\
\hline Universidade Estadual do Oeste do Paraná & $55,17 \%$ & $44,83 \%$ \\
\hline Universidade Estadual do Centro-Oeste & $62,96 \%$ & $37,04 \%$ \\
\hline Universidade Estadual de Ponta Grossa & $42,86 \%$ & $57,14 \%$ \\
\hline Universidade Estadual do Norte do Paraná & $61,54 \%$ & $38,46 \%$ \\
\hline Universidade Estadual do Paraná & $62,07 \%$ & $37,93 \%$ \\
\hline TOTAL & $\mathbf{5 4 , 3 1 \%}$ & $\mathbf{4 5 , 6 9 \%}$ \\
\hline
\end{tabular}

Fonte: A autora (2012) 
Com isso, verifica-se que o número de professores especialistas é predominante em relação aos demais níveis de formação, onde tal fato pode estar associado ao elevado e facilitado número de especializações Lato Sensu enquanto que a Stricto Sensu se restringe aos maiores centros de ensino como a capital do Estado. Essa conclusão pode ser compreendida no estudo de Almeida (2002), onde observa-se que o número de professores formados em Lato Sensu supera ao Stricto Sensu, haja vista que poucas são as Instituições de ensino que oferecem Pós-graduação nessa modalidade e quando ofertam são em números não expressivos, ao contrario da Lato Sensu.

Um dos critérios relevantes analisados nos currículos disponíveis na Plataforma Lattes foi à data de atualização de dados. Cerca de 57\% deles foram atualizados no período de 01/01/2007 a 31/12/2011, equivalentes a 70 currículos. Os $43 \%$ restantes distribuem-se entre aos atualizados posteriormente à 01/01/2012 (38\%) e aos que a partir de 01/01/2007 mantêm-se desatualizados $(5 \%)$.

\subsection{Análises dos Dados dos Currículos}

Para determinação do volume de publicações por parte dos docentes, foram contabilizados seus artigos recentes divulgados em periódicos, seus trabalhos completos apresentados em Anais e Congressos, bem como suas publicações de livros.

\subsubsection{Análise das Participações em Grupos e Projetos de Pesquisa.}

A pesquisa realizada foi satisfatória apresentando cinco das sete instituições analisadas com percentuais acima de 50\% de participação ativa. Este resultado è ainda mais relevante quando considerada sua variação percentual, a qual em média representa 49 pontos percentuais. Quando se refere a qual Instituição o docente está vinculado, a Universidade Estadual de Londrina apresenta-se em destaque com $81 \%$ de participação ativa no meio acadêmico científico, conforme é verificado no Gráfico 01:

Gráfico 01 - Participação docente em grupos e projetos de pesquisa, 2012.

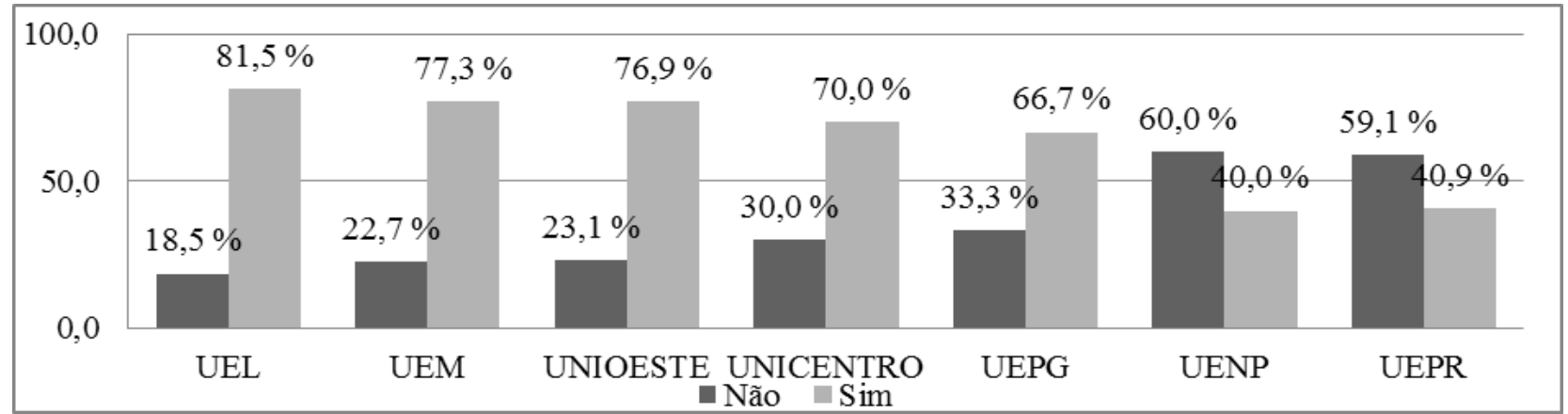

Fonte: A autora (2012)

A Universidade Estadual do Norte do Paraná e a Universidade Estadual do Paraná apresentaram o pior percentual de participações, $40 \%$ e $41 \%$ respectivamente. Uma possível 
explicação para o fato se da em função da recente constituição da UEPR. A UENP pode ter sido prejudicada na pesquisa em função do número reduzido de profissionais analisados - 38\% do total, visto que a Instituição dispõe apenas de uma graduação em Ciências Contábeis entre suas quatro instalações distribuídas pelo Estado.

\subsubsection{Análise das Participações em Atividades de Extensão}

Quanto às participações em atividades de extensão, evidencia-se o quadro de total concentração dessas atividades nas mãos de poucos profissionais docentes, apenas $47 \%$ do total. Dentre as Instituições analisadas, a Universidade Estadual do Norte do Paraná apresentou 100\% de seus professores sem envolvimento algum em projetos de extensão, ao longo de sua formação acadêmica, seguida da Universidade Estadual de Ponta Grossa, com 83,3\%.

Entre as Universidades analisadas destacam-se a Universidade Estadual de Maringá (77,3\%) e a Universidade Estadual do Oeste do Paraná (84,6\%), ambas com altos percentuais quando comparadas as demais. Com isso, pode ser verificado que essas Instituições demonstram alto grau de comprometimento não somente com o ensino, mas também com a comunidade na qual está inserida.

\subsubsection{Análise do Perfil Acadêmico Docente em Relação à Bolsa de Estudos}

Um dos itens adotados pelas instituições de ensino como uma gratificação especial a fim de melhorar significativamente a qualificação de seus acadêmicos e professores é a oferta de Bolsa de Estudos. Apesar de não ser um beneficio estendido a todos os estudantes, este proporciona a criação de oportunidades para muitos, fazendo com que a condição social e financeira do aluno não constitua um empecilho para sua permanência na instituição (FVG, 2012).

Entre as sete Instituições analisadas, destacamos a UEM, onde 50\% de seus docentes ao longo que sua trajetória acadêmica já desenvolveu algum tipo estudo subsidiado por meio de bolsa de estudos. Com relação à UEL, a UNIOESTE, a UNICENTRO e a UEPR estas apresentaram percentuais semelhantes, equivalente a $30 \%$ dos professores. As demais não alcançaram 10\%.

\subsubsection{Análise da Participação Docente em Bancas de Mestrado e Doutorado}

O índice de docentes que participam de bancas de mestrado e doutorado representa $10 \%$ do total. Essa baixa participação pode ser justificada pelos reduzidos números de especializações Stricto Sensu oferecidas no país, conforme abordado nesta pesquisa. Entre as Instituições analisadas a UEL foi à única que apresentou participação considerável $42 \%$, possivelmente em função do número total de docentes com formação Doutorado, 13 no total; sendo que nas demais instituições analisadas a quantidade de profissionais não ultrapassa a 07. 


\subsubsection{Análise das Publicações Docentes}

Conforme foi abordado no referencial teórico, a produção científica na área da contabilidade é bastante recente, se comparada com as demais áreas do conhecimento, tendo sido mais intensificada a partir dos anos 2000. Segundo Bezerra (2010, p.05): "no Brasil em 20 anos aproximadamente, a pesquisa científica mudou de $0,48 \%$ para $1,92 \%$, de toda produção mundial em todas as áreas do conhecimento, o qual fez ocupar o $13^{\circ}$ lugar no ranking mundial de 1980 a $2008^{\prime \prime}$.

\subsubsection{Publicações de Artigos em Periódicos}

Uma das informações selecionadas para determinar os objetivos da pesquisa foi o período de maior participação docente em publicações de periódicos, por meio da divulgação de seus artigos pesquisados. Assim, os índices identificados foram satisfatórios, identificando que 19,8 \% dos artigos desenvolvidos pelos pesquisados foram publicados a partir de 2011, conforme apresenta o Gráfico 02.

Gráfico 02 - Publicação de artigos em periódicos - mestres e doutores, 2007 a 2011.

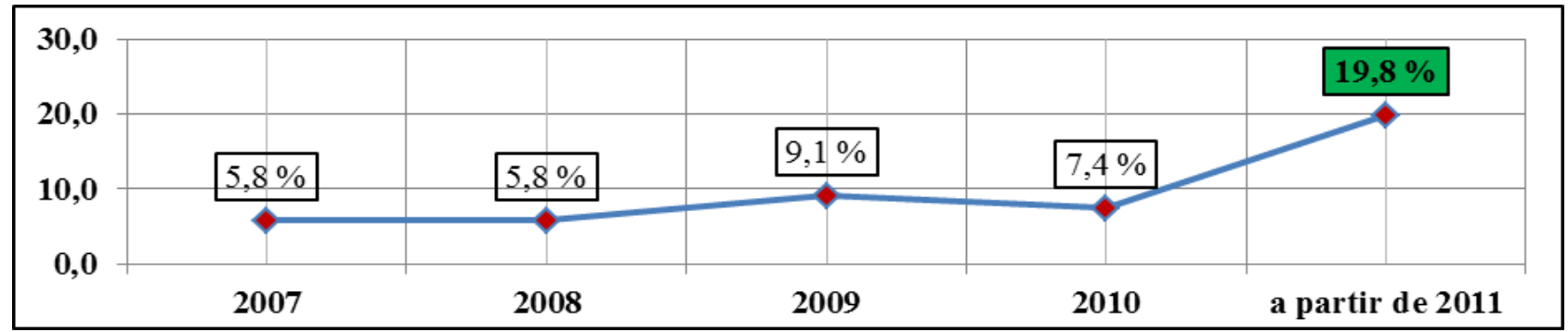

Fonte: A autora (2012)

Em relação ao último artigo publicado em periódico, os dados indicam que 35,5\% dos pesquisados nunca publicaram. Esse percentual sobe para 52,1\% quando considerados em conjunto aqueles cujas publicações são anteriores a 31/12/2006. Ou seja, apenas 47,9\% dos investigados publicaram artigos em periódico no período compreendido entre 2007 e a partir de janeiro de 2011. Este é um percentual preocupante, visto que 63 docentes entre as sete instituições analisadas sequer publicaram um artigo em periódico desde janeiro de 2007.

A produção científica é um importante instrumento para o progresso social e tecnológico, uma vez que estimula ao debate acerca de determinado tema, e posteriormente resulta em novas produções científicas. Dessa forma, "redigir e publicar um artigo científico certamente trará um aprofundamento na pesquisa desenvolvida e enriquecerá o currículo de seu autor”. (UFSM, 2012).

\subsubsection{Publicações de Trabalhos Completos em Anais e Congressos}

Tão importante como publicar artigos em periódicos, assim é divulgar seus trabalhos completos em Anais e Congressos. O Quadro 02 apresenta a quantidade de publicações realizadas pelos docentes das Instituições pesquisadas nos últimos anos. 
Quadro 02 - Publicação de trabalhos completos em anais e congressos - Mestres e Doutores das Universidades Estaduais do Paraná

\begin{tabular}{|l|c|c|c|c|c|c|c|}
\hline \multicolumn{1}{|c|}{ PERÍODO } & UEL & UEM & UNIOESTE & UNICENTRO & UEPG & UENP & UEPR \\
\hline Nenhum & 2 & 3 & 3 & 6 & 7 & 2 & 16 \\
\hline Ant. à 31/12/2006 & 6 & 8 & 1 & 2 & 1 & 1 & 1 \\
\hline 2007 & 2 & 0 & 0 & 1 & 1 & 0 & 0 \\
\hline 2008 & 3 & 1 & 0 & 4 & 1 & 0 & 1 \\
\hline 2009 & 4 & 0 & 0 & 2 & 0 & 1 & 0 \\
\hline 2010 & 4 & 3 & 3 & 0 & 0 & 1 & 0 \\
\hline A partir de 2011 & 6 & 7 & 6 & 5 & 2 & 0 & 4 \\
\hline \multicolumn{1}{|c|}{ TOTAL } & $\mathbf{2 7}$ & $\mathbf{2 2}$ & $\mathbf{1 3}$ & $\mathbf{2 0}$ & $\mathbf{1 2}$ & $\mathbf{5}$ & $\mathbf{2 2}$ \\
\hline
\end{tabular}

Fonte: A autora (2012)

O período que trata a presente pesquisa compreende aos últimos cinco anos. Em cada currículo foi observado o campo: trabalhos completos publicados em anais e congressos, selecionando o ano da divulgação mais recente. Quanto ao volume de publicação observa-se que a partir do ano de 2011 foi maior, representando 24,8\% do total. Entretanto, se obervado o Tabela 01 verifica-se que o índice de maior representatividade foi de $32,2 \%$, indicando que 39 dos docentes analisados nunca publicaram seus trabalhos completos em Anais ou Congressos.

\subsubsection{Livros Publicados ou Organizados}

Segundo a literatura, a essência da pesquisa científica é a produção de conhecimento e a bibliografia científica é a manifestação desse conhecimento. Dessa forma, publicar os resultados do seu trabalho é um comprometimento, pois são eles que justificam sua existência (CUNHA; JUNIOR, 2008).

De acordo com o Gráfico 03, pode-se observar que houve um equilíbrio no que se refere ao número de livros publicados ou organizados: cerca de 63,6\% dos professores analisados nunca divulgaram seu trabalhos por meio da publicação de livros; sendo que entre as sete Universidades Estaduais do Paraná, apenas a Universidade Estadual do Oeste do Paraná apresentou percentual abaixo de $50 \%$.

Gráfico 03 - Docentes que nunca organizaram ou publicaram livros - Universidades Estaduais do Paraná

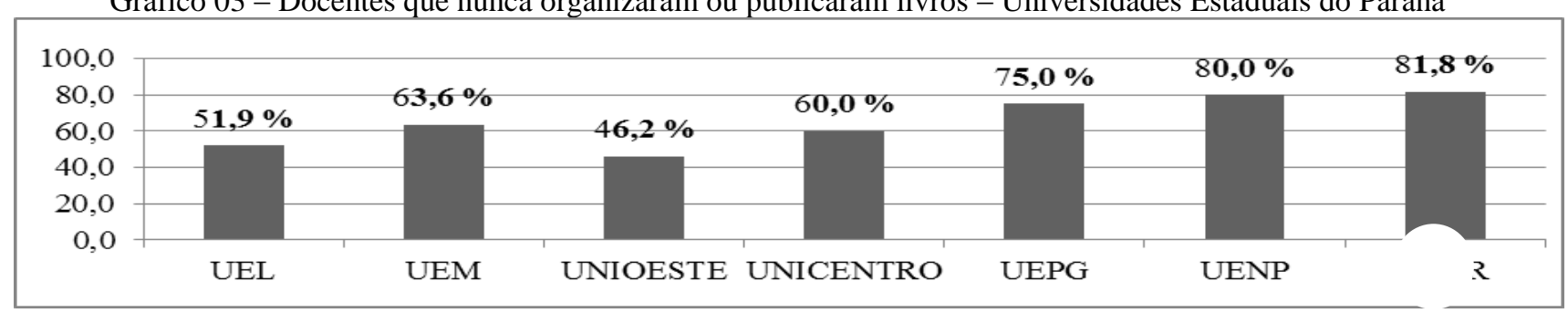

Fonte: A autora (2012)

Apesar de não ser um hábito adotado por todos os profissionais docentes, a publicação de livros é um importante meio de comunicação, tanto para o desenvolvimento social como para o próprio crescimento intelectual. Entretanto, em função de seu alto custo de confecção, o faz dele uma divulgação nem sempre utilizada no meio acadêmico (ANDRÉ; COSTAS, 2004). 


\section{Considerações Finais}

Ao longo da pesquisa, constatou-se que $72 \%$ das instituições analisadas possuem seu corpo docente formado com professores Lato Sensu, representando 151 especialistas em um total de 272 docentes analisados. Os demais $28 \%$ são distribuídos entre o número de 90 mestres e 31 doutores. Identificou-se também que a instituição que apresenta o maior percentual de professores com formação Strictu Sensu foi a Universidade Estadual de Maringá, com 59,46\%. Já a Universidade Estadual do Centro Oeste apresentou o maior número de professores com formação Lato Sensu, $63 \%$ do total.

Com relação às participações em grupos e projetos de pesquisa, o estudo demonstrou que este vem se desenvolvendo de maneira satisfatória em cinco das sete Instituições analisadas, as quais representam uma participação ativa de mais de 50\%. Entretanto, quando se trata das participações em projetos de extensão, notou-se uma grande deficiência, onde a concentração dessas atividades nas mãos de poucos profissionais docentes.

A pesquisa revelou também, um fato um tanto quanto curioso, onde $74 \%$ dos professores analisados não possuem e nunca possuíram nenhum tipo de remuneração durante seus estudos, como por exemplo, o incentivo com bolsa de estudos, situação esta que se repete na atividade de monitoria, onde esta nem sempre é uma pratica adotada por todas as instituições de ensino.

Embora publicar livros faça parte da manifestação do conhecimento cientifico, constatou-se um percentual extremamente baixo de organizações ou publicações bibliográficas em todas as Instituições analisadas, chegando o total $81,8 \%$ de professores que nunca publicaram ou organizaram algum livro.

Já em relação ao número de publicações realizadas pelos docentes analisados, o estudo revelou que a maior concentração é a partir do ano de 2011, seja pela publicação de artigos em periódicos ou pela divulgação de trabalhos completos em Anais e Congressos. Um índice importante, pois revela que os professores mantém ativamente o desenvolvimento de pesquisas, bem como a torna conhecida no meio acadêmico.

Dessa forma, com os resultados da pesquisa pode-se concluir que o volume de contribuições acadêmicas desenvolvidas pelas universidades estaduais do Paraná no periodo de 2007 a 2012 foi relativamente baixo, onde sua concentração apresenta-se restritita aos grandes centros como a UEL e UEM. Para tanto, nota-se que a frequência de publicacoes apesar de baixa, é um indice que cresce gradativamente ao longo dos anos como e o caso de divulgacao em artigos e periódicos. Resultado este, contrario a Teoria do Capital Humano, onde as habilidades humanas devem ser aperfeiçoadas a medida que enriquece o seu capital intelectual. 
Por fim, deve-se considerar como limitação desta pesquisa a data de atualização dos currículos utilizados neste trabalho, visto a data do download bem como a atualização cadastral de cada profissional, podem ter gerado classificações inconsistentes. Vale observar também que, dado que o universo aqui estudado é representado por uma amostra não probabilística, a qual se refere às sete universidades estaduais do Paraná, as inferências tomadas devem ser tratadas com certas restrições, embora valha lembrar que tal amostra englobe $94,5 \%$ dos profissionais enquadrados no estudo.

Lembrando que as contribuições acadêmicas dos mestres e doutores do departamento de Ciências Contábeis das Universidades Estaduais do Paraná é o desenvolvimento ativo de pesquisas científicas e tecnológicas, o engajamento em ações sociais na elaboração de projetos e serviços multidisciplinares de extensão vinculados ao curso, o desenvolvimento de atividades vinculadas ao meio acadêmico, etc., sendo estes, um dos critérios de avaliação do ensino superior atribuídos pelo Ministério da Educação.

\section{Abstract}

This article presents Academic contributions of masters and doctors of the Department of Accountancy of State universities of Paraná, on the basis of the curricula offered in Lattes platform. Academic contributions can developed in countless ways, either by participating in groups and research projects, extension activities, or by the publications of articles in academia. However, note that only their development is not enough. It is necessary that in addition to its creation, this knowledge comes within reach of the entire academic community. The methodology applied in this study characterized as descriptive, bibliographical and survey type with qualitative and quantitative approach. The population comprises all teachers and doctors from the Accounting Department of the seven State universities of Paraná, a total of 128 professionals. For the survey was selected a sample of 121 teachers; These professionals that made available on the website of CNPq curricular information.

Key-words: Teachers, State Universities of Paraná, Scientific Research.

\section{Referências}

ALMEIDA, E. V. Educação de Adultos Trabalhadores: Metodologias do Ensino-Aprendizagem, Itinerário Formativo e Capacitação dos Professores. Fonte Primária de Informação para Pesquisa Apoiada pela FAPESP. Disponível em: < http://www.bv.fapesp.br/pt/projetos-politicas-publicas>. Acesso em: 10 ago. 2012.

ANDRÉ, S.; COSTA, A. C. G. Educação para o desenvolvimento humano. São Paulo: Saraiva, Instituto Ayrton Senna, 2004.

BEIRÃO, P. S. L. A Importância da Iniciação Científica para o Aluno de Graduação. Boletim UFMG, Belo Horizonte/MG, ano 24, n.1208, p.02, 28 outubro 1998. Disponível em: 〈http://www.ufmg.br/boletim〉. Acesso em: 15 jan. 2012.

BEUREN, I. M. (Org. e colaboradora). Como elaborar trabalhos monográficos em Contabilidade - teoria e prática.

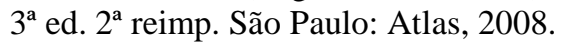


BEZERRA, A. M. A Formação continuada do corpo docente e sua importância para a Pesquisa: Um estudo empírico das IES Publicas - UEMS e UFGD dos cursos de Contabilidade de Mato Grosso do Sul. Disponível em: < http://www.classecontabil.com.br/site/trabalhos/FormacaoContinuada.pdf>. Acesso em: 10/09/2012.

BRITO, L. Contábeis tem mercado de trabalho diversificado e boa empregabilidade. Globo.com. São Paulo, 30 janeiro 2007. Disponível em: < http://g1.globo.com/Noticias/Vestibular.html>. Acesso em: 13/03/2012.

CATTANI, A. D. Teoria do capital Humano. Século XXI. Rio de Janeiro, 01 março 2002. Disponível em: <http://portalmultirio.rio.rj.gov.br>. Acesso em: 27/03/2012.

CNPQ, Conselho Nacional de Desenvolvimento Cientifico e Tecnológico. Plataforma Lattes. Disponível em:< http://www.cnpq.br>. Acesso em: 22 mai. 2011.

COSTA, M. L. F. História e Políticas para o Ensino Superior a Distancia no Estado do Paraná. Maringá/PR, 2011. Disponível em:< http://www.utp.br/Cadernos_de_Pesquisa.pdf $>$. Acesso em:13 mar. 2012.

CUNHA, J. V. A.; CORNACHIONE JUNIOR, E. B. Contribuições Acadêmicas dos Doutores em Ciências Contábeis: Uma Análise dos Curricula Lattes. In: CONGRESSO USP CONTROLADORIA E CONTABILIDADE,8., 2008, São Paulo, CONGRESSO USP INICIAÇÃO CIENTÍFICA EM CONTABILIDADE, 5., 2008, Anais e Palestras, São Paulo: USP, 2008. Disponível em:<http://www.congressousp.fipecafi.org/artigos82008/454.pdf>. Acesso em: 17 jan. 2012.

CUNHA, J. V. A. Doutores em Ciências Contábeis da FEA/USP: análise sob a óptica da teoria do capital humano. Tese de Doutorado - Faculdade de economia e Contabilidade da Universidade de São Paulo. São Paulo: FEA/USP, 2007. Disponível em:<http://www.teses.usp.br/teses>. Acesso em: 17/01/2012.

FERREIRA, A. B. H. Mini Aurélio Século XXI Escolar: O Minidicionário da língua portuguesa. 4. ed. Rio de Janeiro: Nova Fronteira, 2001.

FURLAN, F.; NASCIMENTO, F. R. A Pesquisa e o Professor: Desafio Atual da Educação. In: CONGRESSO INTERNACIONAL DE EDUCAÇÃO, 2., 2006 Santa Maria/RS; JORNADA NACIONAL DE EDUCAÇÃO. Anais e Palestras. Santa Maria/RS: UNIFRA, 2006. Disponível em:〈http://www.unifra.br/eventos/jornadaeducacao2006.pdf〉. Acesso em: 15 jan. 2012.

GIL, A. C. Didática do Ensino Superior. 1. ed. São Paulo: Atlas, 2011.

INEP, Instituto Nacional de Estudos e Pesquisa Educacionais Anísio Teixeira. Disponível em: < http://portal.inep.gov.br/>. Acesso em: 13 ago. 2012.

JARDILINO, J. R. L.; AMARAL, D. J.; LIMA, D. F. A Interação Professor-Aluno em Sala de Aula no Ensino Superior: o curso de administração de empresas. Revista Diálogo Educacional, Curitiba, v.10, n.29, p. 101-119, janeiro a abril 2010.

JORGE, M. O PIBIC nas universidades estaduais do Paraná (1995-2005). In: CONGRESSO NACIONAL DA EDUCAÇÃO - EDUCERE, 7., 2007, Curitiba, ENCONTRO NACIONAL DE ATENDIMENTO AO ESCOLAR HOSPITALAR, 5., Anais e Palestras, 2007, Curitiba: PUCPR, 2007. Disponível em:<

http://www.pucpr.br/eventos/educere/educere2007/index.html>. Acesso em: 27 mar. 2012.

KLEIN, T. C. Curso Prático de Didática Geral, para professores dos níveis de ensino Médio e Superior. Rio de Janeiro: Aurora, 1975

LEMES, R. R. Currículo Lattes do CNPq. PROPESQ UFRGS 2008. Slide. Disponível em: <http://www.propesq.ufrgs.br/eventos.pdf>. Acesso em: 15 jan. 2012.

MEC, Ministério da Educação. Censo da Educação Superior: Divulgação dos primeiros resultados do censo da educação superior 2010. Disponível em:< http://portal.mec.gov.br>. Acesso em: 27 mar. 2012.

NOSSA, V. Ensino da Contabilidade no Brasil: Uma análise critica da formação do corpo docente. 157 f. Dissertação de Mestrado em Controladoria e Contabilidade - Setor de Ciências Sociais aplicadas, Universidade de São Paulo. São Paulo, 1999. Disponível em:< http://www.fucape.br.pdf>. Acesso em: 18 set. 2011.

PARANÁ, Governo do Estado. Modelo paranaense de universidades estaduais é referência nacional. Curitiba, 09 março 2012. Disponível em:< http://www.seti.pr.gov.br>. Acesso em: 23 mar. 2012. 
PESQUISA A força do ensino superior no Mercado de trabalho. São Paulo: SEMESP, 2008. Disponível em: < http://www.semesp.org.br> Acesso em: 21 mai. 2011.

RODRIGUES, A. T. L. Desafios Acadêmicos da Profissão: Exame de Suficiência e Educação Continuada. Disponível em:< http://www.ececon.com.br/arquivos/ana.pdf $>$. Acesso em: 27 mar. 2012.

RUCKSTADTER, V. C. M. Educação e Economia nos anos 1990: a resignificação da teoria do capital humano. In: SEMINÁRIO NACIONAL ESTADOS E POLITICAS SOCIAIS NO BRASIL, 2., Anais e Palestras, Cascavel/PR:

UNIOESTE, 2005. Disponível em:<http://cac-php.unioeste.br/projetos.pdf>. Acesso em 15 jan. 2012.

TEIXEIRA, A. Uma perspectiva da educação superior no Brasil. Revista Brasileira de Estudos Pedagógicos, Rio de Janeiro, v. 50, n. 111, p. 21-81, jul./set. 1969. Disponível em:<

http://www.bvanisioteixeira.ufba.br/artigos/perspectiva.html>. Acesso em: 03 fev. 2012.

UFSM, Universidade Federal de Santa Maria. Qual a importância de publicar artigos científicos? Disponível em: <http://www.ufsm.br/revistadireito>. Acesso em: 16 set. 2012

VASCONCELLOS, C. S. Disciplina: construção da disciplina consciente e interativa em sala de aula e na escola. 7.ed. São Paulo: Libertad, 1996.

VESCO, D. G. D. O Ensino da Contabilidade no Brasil: Problemas e Soluções. Revista Eletrônica Científica UFTPR, v.1, n.1, p.80-84, 2006. Disponível em:<http://revistas.utfpr.edu.br>. Acesso em: 13/03/2012.

\section{Dados dos autores}

Nome completo: Patricia Taradenko

Filiação Institucional: UNICENTRO

Departamento: Ciências Sociais Aplicadas: Ciências Contábeis

Função ou cargo ocupado: Acadêmica na especialização Gestão Financeira de Negócios

Endereço completo para correspondência: Rua Dr Xavier da Silva, 999 - Centro, Ivaí - PR

Telefone: (42) 32471437; (42)99171620

e-mail:paty_taradenko@hotmail.com

Nome completo: Ana Léa Macohon Klosowski

Filiação Institucional: UNICENTRO

Departamento: Departamento de Ciências Contábeis

Função ou cargo ocupado: Orientadora: MSc. em Contabilidade Avançada

Endereço completo para correspondência:

Telefone: (42) 9974-6565

e-mail: alea@irati.unicentro.br

Submetido em: 17/02/2014

Aceito em: 18/12/2014 